Article

\title{
Impact of Trust, Commitment, and Openness on Research Project Performance: Case Study in a Research Institute
}

\author{
Masoumeh Ghazinejad, Bassam A. Hussein and Youcef J. -T. Zidane * \\ Department of Mechanical and Industrial Engineering, Faculty of Engineering, Norwegian University of Science \\ and Technology, Trondheim 7491, Norway; masomeh.gh@gmail.com (M.G.); bassam.hussein@ntnu.no (B.A.H.) \\ * Correspondence: youcef.zidane@ntnu.no; Tel.: +47-735-97-121
}

Received: 1 December 2017; Accepted: 26 January 2018; Published: 30 January 2018

\begin{abstract}
This study focuses on three important shared values—trust, openness, and commitment—and examines the impact of these values on project performance and outcomes, specifically for science and innovation research projects. To this end, 12 in-depth interviews were conducted with researchers, research managers, and research leaders at the largest research institution in Scandinavia. The findings indicate that the three values (trust, openness, and commitment) are practiced at this research institution and are essential to effective teamwork. The findings also show that trust and openness promote shared understanding, and encourage commitment.
\end{abstract}

Keywords: research projects; organizational culture; commitment; trust; openness

\section{Introduction}

The purpose of this paper is to present the results of a study that was conducted in a major research institute in Norway. The main activities of the research institute are centered around contract research projects. Every year the institute performs more than 9000 research projects for some 3000 clients. The main objective of this type of research is to develop knowledge and technologies that can be applied and brought into practical use, and to contribute to value creation and increased competitiveness within the private and public sectors.

In the last years, there has been a strong and increasing tendency among project management researchers to move away from the traditional views of predictability and linearity in project practice to one that highlights the complex nature of human interrelations (Small and Walker 2011). The underlying assumption under this tendency is that the project is a complex setting embedded in a social-cultural context and characterized by human interactions and tension between predictability and control (Cicmil et al. 2006). Bearing in mind that projects are submerged in such a complicated context, then project success is not only dependent on proper planning and control but also is dependent on a number of organizational factors, and these factors are often referred to as organizational culture. Understanding organizational culture is important for understanding the project as a complex social process. Organizational culture can be defined as a pattern of shared values and beliefs (Erkutlu 2012). According to Alvesson (2002), good cultures are specified by norms and values such as teamwork, honesty, commitment to the organization, and pride in one's work.

The purpose of this study is: (1) to explore the impact of values such as trust, commitment, and openness on research project outcomes in the case initiation; and (2) to identify some remedies that project managers can apply to increase the positive effects of trust, commitment, and openness on research project performance and outcomes.

The study is limited to examining trust, commitment, and openness because, firstly, we wanted to limit the scope of the study and, secondly and more importantly, in project management literature, 
values such as trust, openness, and commitment are viewed as important success factors in projects in general. For example, it has been suggested by (Aubert and Kelsey 2000) that trust can facilitate the exchange of information and reduce control and its associated cost, as well as make working relationships more efficient. Trust has also a strong positive influence on the strength of relationships and ultimately has a positive effect on project outcome (Rousseau et al. 1998). Openness refers to the level of transparency in sharing task-relevant information (Schein 2010). Openness facilitates the alignment of goals and expectations and helps team members to achieve a common and mutual understanding of the project scope (McLeod and MacDonell 2011). Open and adequate communication helps to develop shared understanding, improves the atmosphere of the relationship, fosters commitment, ensures that deadlines are respected, and enhances trust between the partners (Dyer and Chu 2003; Bstieler 2006; Zidane et al. 2016). In addition, openness reduces mistrust and conflict of interest and improves project performance (Turner and Müller 2004). The importance of commitment (organizational commitment and commitment of the project organization) to project success is widely considered an important success factor (Hussein and Hafseld 2016).

Hussein (2013) identified a combination of top management commitment and project team commitment as a force driving the successful development of projects. Fowler and Horan (2007) identified top management commitment as a critical success factor and suggested its dominance in the planning phase of the project lifecycle. Pinto and Prescott (1988) emphasized the importance of top management commitment in projects as it plays various roles in the organization, for example, influencing attitudes, creating a positive context for change, overseeing the development of the project, and ensuring the availability of resources.

The paper is organized as follows: In Section 2 we explain the meaning and interpretation of trust, commitment, and openness in literature and explain their significance in managing projects. In Section 3 we explain the methodology used in the study. Section 4 presents the findings and discussions of these findings. Section 5 presents the conclusions.

\section{Literature Review}

\subsection{Trust}

Rousseau et al. (1998) defined trust as a complex phenomenon that enables cooperative behavior, reduces harmful conflict, decreases transaction costs, and promotes effective responses to crisis. There are three basic forms of trust (Kadefors 2004; Rousseau et al. 1998). (1) Calculus-based trust is when the trustor (the trusting party) perceives that an action that is going to be performed is beneficial to him or her. In this kind of trust, individuals are motivated primarily by economic self-interest; (2) Relational trust appears between individuals who interact repeatedly over time; (3) In institution-based trust, trust refers to the role of the institution in shaping the conditions necessary to create trust. Similarly, trust is needed when there are uncertainties, in order to have a successful outcome (Smyth et al. 2010). Since trust is believed to have a positive effect for the duration of a project, it is relevant to try to assess its overall effect. A high level of trust between clients and project design teams reduces transaction costs and maximizes creativity and problem-solving (Smyth et al. 2010). Trust-based relationships will not easily weaken because of differences of opinion. Trust enables partners to overcome difficulties and facilitates mutual understanding (Bstieler 2006). Therefore, trust can help to strengthen and improve the relationships among project partners, and as a result bring a variety of benefits for the project as a whole (Wong et al. 2008).

\subsection{Openness}

Openness refers to the level of transparency in sharing task-relevant information (Schein 2010). Openness facilitates the alignment of goals and expectations and help team members to achieve a common and mutual understanding of the project scope (McLeod and MacDonell 2011). Open and adequate communication helps to develop a shared understanding, improves the atmosphere 
of the relationship, fosters commitment, ensures that deadlines are respected, and enhances trust between the partners (Dyer and Chu 2003; Bstieler 2006; Zidane et al. 2016). In addition, openness reduces mistrust and conflict of interest and improves project performance (Turner and Müller 2004). Organizational policies and practices may constrain the appropriation of innovations, such as new standard methods, techniques, or tools (McLeod and MacDonell 2011). To overcome these difficulties, a project team should have an organizational culture that supports individual efforts and ensures that the required information is shared and that there is direct communication among all members of the team (Cserháti and Szabó 2014).

\subsection{Commitment}

Mowday et al. (1979) defined commitment as the strength of an individual's identification with and involvement in an organization. It has three components: a strong belief in and acceptance of the organizational goals and values, a willingness to exert considerable effort on behalf of the organization, and a desire to maintain organizational membership. Commitment is a strong and important concept with considerable relevance for both employees and organizations. For employees, commitment to work in an organization represents a positive relationship (Mowday 1998). Commitment is classified in three forms: affective, continuance, and normative. Affective commitment refers to an individual's emotional attachment to the organization (Meyer et al. 1993). Continuance commitment means being associated with the organization based on the cost of leaving or the rewards for staying. Normative commitment reflects the feeling of being obligated to stay in the organization (Mahdi et al. 2014). Organizational commitment as the organizational support has a positive impact on achieving project objectives (Basu et al. 2002). In addition, organizational commitment increases an individual's feeling of involvement and sense of belonging (Zehir et al. 2012). Commitment has a vital role in reducing variance and slippage in project cost and schedule (Gulzar et al. 2012).

\section{Methodology}

This study used semi-structured interviews as a data-collection technique. We conducted face-to-face interviews with 12 individuals from the research institution who have been working on various types of research projects. The interviewees determined the direction and content of the interview within a broader framework. Interviews lasted between 30 and $40 \mathrm{~min}$. The interviewees had from 8 to 20 years of experience in research. Their fields of research are project management, production and logistics, financing, economics, and health and safety. All interviewees are senior research scientists, and half are researcher managers or research directors. As mentioned, this study was conducted in a research institution. All respondents were working on research projects at the time of the study. The 12 interviews were sufficient in providing rich insights into the impact of the shared values of trust, commitment, and openness on the performance and outcome of research projects.

Validity in qualitative research is described as whether a measure of a concept really measures that concept (Koufteros et al. 2010). In qualitative research, theorists often appeal to the criterion of "respondent validation"; in other words, researchers' interpretations should be recognizable when presented to study participants (Van Den Hooff and De Ridder 2004). With this in mind, all of the interviews were recorded with the interviewees' permission, then all of the interviews were transcribed. Having face-to-face interviews helped to avoid any misunderstanding. When interviewees did not understand questions or main concepts, they were explained to make sure that they were clear. At the core of qualitative analysis are the related processes of describing phenomena, classifying them, and seeing how concepts are interconnected (Dey 1993). After completing the interviews, they were transcribed into documents, and all transcripts were carefully checked against the audio recordings to ensure accuracy. 


\section{Findings and Discussion}

\subsection{Impact of Trust}

The findings suggest that researchers, research managers, and leaders value trust as being vital to research projects success. The findings show that trust in the researchers' ability to complete their tasks increases the level of involvement in the project.

"If I think she [leader] is not confident about what I am doing, then I am losing confidence as well."

The findings show that trust at different levels affects the project. For example, in innovative or problem-solving projects, a high level of trust between clients and the project group reduces the transaction costs in the early phase of the project. This finding is in line with findings reported by Smyth et al. (2010), who proved that a high level of trust between clients and the project team reduces transaction costs and maximizes creativity and problem-solving.

These findings also indicate that long-term relationships with clients contributes to establishing a level of trust.

"Long-term working with companies and also inside, establishes a level of trust and reduces transactional cost in the project."

The findings show that in the early phase of a project, researchers from different departments who participate in the project need to know each other first. When researchers do not know each other, it takes longer to build trust.

"We trust each other inside the department, but being involved in the project with other departments, we need to create trust, because we do not know each other."

The findings show that trust can affect the project through knowledge sharing. Without trust, researchers do not share their knowledge, which hinders the progress of the project. Some informants believe that researchers are willing to share their knowledge, but they have many projects and do not have time for sharing.

"People share their knowledge very well. They just do not have time to share the knowledge."

"I trust my colleagues; it is not good for our company to be protective. I think trust is individual."

The findings show that research projects do not need to have a reward system to create trust and increase productivity. However, based on the literature, trust can be enhanced through a reward system that influences people's perception of each other's motivation and the value of joint performance (Ferrin and Dirks 2003). Therefore, a reward system cannot be considered as a motivational issue for the organization under study.

"I do not think a reward system would help. I do not think a reward system would impact on what we want."

\subsection{Impact of Commitment}

The findings from this study suggest that researchers, research managers, and leaders value commitment as a vital element to a research project's success. Moreover, the level of commitment may affect the success or failure of a project. It is a common approach for researchers to have priorities for their tasks based on their interest in the project. In other words, they prefer to work on projects that they have an interest in. Freedom to do the projects that they are interested in motivates them to be committed to the projects. Thus, the level of commitment depends on the level of interest. 
"We have freedom with responsibilities. There is freedom of choice in selecting the project in our field."

The findings show that in addition to the importance of researchers' freedom motivating them to be committed to projects, knowing and understanding the objectives of the organization can also encourage commitment. Researchers who believe in the organization's goals and values are committed to the work.

"I think making society better, as a slogan in our organization, encourages commitment to the project."

The findings show that in addition to team members' commitment, the organization's support is also very important and affects project performance.

Organizational support is necessary to encourage researchers' commitment to the project. The majority of researchers were satisfied working at this organization. They were proud of their organization, and that was a big motivation for them to be committed to projects.

"The organization has shown commitment, both in financial terms and appreciation for the job you do, and they see you."

The findings show that researchers have to be flexible, because in project work they are faced with many unexpected things. As mentioned, researchers work on different projects simultaneously, and they have priorities for their projects. They cannot be involved in all of the projects as much as they would like. In the middle of a project, they will make an excuse for not performing their own tasks. Leaders try to deal with that problem by replacing them with somebody else or dividing the work among team members. These problems affect project duration and cause delay.

"Commitment is not enough, you should be flexible."

"Researchers are too busy to contribute as much as they would like. We [research managers] try to deal with that."

The findings show that when researchers feel a sense of belonging in the organization, they have a stronger sense of commitment to the project. For employees, commitment to work and the organization represents a positive relationship (Mowday 1998).

"The motivation for our employees is that they understand they are part of the organization."

\subsection{Impact of Openness}

The informants believe that their culture is one of openness. The findings also show that through open communication, researchers share information that affects project outcome. Through communication, they ensure that deadlines are respected. According to the literature, through communication, people share information that is critical to the successful implementation of projects (Pinto and Pinto 1990).

"Openness is one of the things that actually helps us. When we work together as a team, we need to share our knowledge."

"With open communication, everybody can have a voice, everybody will be allowed to have an opinion. Involvement, I think, is important."

Findings show that in research organizations with a high degree of openness, such as open communication with colleagues and managers, people can solve problems, and this has a direct effect on project outcome. In addition, through effective communication, researchers share their knowledge, which affects project performance. 
"If you are not open enough, you struggle in your problem. This affects the duration of the project."

The findings show that transparency leads to teams having the whole picture of the project. If researchers know the whole project, they will have a better understanding of the project. This has a positive effect on project outcome.

"You get the task that is part of the bigger task. We make better results if we can see part of the whole picture."

Openness helps to avoid misunderstanding, particularly in the early phase of a project.

"Openness is important to avoid misunderstanding."

"Openness in the research organization is quite important. Getting efficient information from others, meeting and discussing things."

\subsection{Possible Remedies}

This study sought to examine the impact of shared values on project performance and outcomes. The problems seen in organizations can be divided into four categories. We will suggest some remedies for the problems in order to increase the positive effects of trust, commitment, and openness. Before discussing the problems and remedies, it is necessary to explain the role of the project management's leadership style in increasing the positive effects of trust, commitment, and openness.

The findings show that project management has an important role in involving team members, communicating effectively, and collaborating inside and outside of the organization. Leadership factors, as well as organizational factors, can directly impact project performance (de Oliveira et al. 2012). It is very important to have good relationships and a good working climate and environment. Project managers in leadership roles can create an effective environment for project teams (Turner and Müller 2005). Organizations need to assess their cultural orientation and make changes rather than keep the culture as an invisible and non-measurable element. Project management has an essential role in creating a team culture to achieve project goals and group norms (Yazici 2009). The following outlines some situations that are needed in an organization to consider possible remedies.

A summary of the identified problems and possible remedies are presented in Table 1; more discussion about the identified problems and the remedies are discussed later.

Table 1. Summary of possible remedies for problems.

\begin{tabular}{cll}
\hline Number & \multicolumn{1}{c}{ Identified Problems } & \multicolumn{1}{c}{ Remedies } \\
\hline 1 & $\begin{array}{l}\text { Projects postponed because researchers' commitment } \\
\text { depends on the project field and their interests. }\end{array}$ & $\begin{array}{l}\text { Increase commitment to projects with project } \\
\text { management's effective communication. }\end{array}$ \\
\hline 2 & $\begin{array}{l}\text { Projects delayed due to researchers not being } \\
\text { involved in projects equally. }\end{array}$ & $\begin{array}{l}\text { Project managers must know team competency by } \\
\text { increasing communication. }\end{array}$ \\
\hline 3 & $\begin{array}{l}\text { Lack of trust and misunderstanding in the early } \\
\text { phase has negative effects on project performance } \\
\text { and outcome. }\end{array}$ & $\begin{array}{l}\text { Project managers must allocate much more time in } \\
\text { the early phase in order to avoid misunderstanding } \\
\text { and build trust. }\end{array}$ \\
\hline & $\begin{array}{l}\text { Project managers do not have enough time to control } \\
\text { the progress and make decisions before the project } \\
\text { is postponed. }\end{array}$ & $\begin{array}{l}\text { Project managers, by delegating their responsibilities, } \\
\text { can help and support teams. Shared leadership is } \\
\text { appropriate for knowledge-based work like } \\
\text { research projects. }\end{array}$ \\
\hline
\end{tabular}

For the first problem, the findings show that researchers work on several projects simultaneously. Their priories for their tasks are based on their interest in the project. However, researchers give up some projects in the middle, because they do not have enough time for all of their tasks. Then project managers have to replace them with somebody else or divide their work among the group. This problem may affect the project outcome, and causes some projects to be postponed. In addition, if people just follow their own interests, it creates a challenge for team members and management for a long time. 
"Lack of a project manager's competency to push enough in the proper manner leads to delay."

"If we do not change our way, the market is gone, and then people do not have projects."

This shows that lack of communication creates some problems.

"People do not speak aloud. If we have a problem, I think it is difficult to bring it up."

One of the main responsibilities of project managers is to motivate their teams to complete projects on time. Project managers need leadership skills to develop researchers' interest in different kinds of projects. Informants 6 and 8 emphasized the project management dialogue. Project managers must have better communication with team members. Research managers believe that project managers can motivate researchers through effective communication. The literature review shows that culture becomes a critical factor in defining project success, and project managers should understand the different organizational cultures that may affect a project (PMI 2013). The right leadership style of project managers can improve organizational commitment (Limsila and Ogunlana 2008). Finally, the appropriate style of leadership motivates individuals and teams to work effectively and efficiently toward the performance goals that the project has to achieve (Rees 2008). Project managers using the appropriate leadership style can overcome these difficulties. Transformational leadership is committed to organizational goals and seeks to encourage people's commitment to the results (Bass 1999; García-Morales et al. 2012). Thus, there is a correlation between the manager's leadership style and the employees' commitment and motivation (Turner and Müller 2005).

A second problem identified in this study is that project managers select team members based on their prior work experience. This leads to some people having many projects to do and some not having enough. This shows a lack of communication between project managers and people in the organization. Then the researchers in different groups are not allocated to projects equally. In addition, for some projects, the big challenge was that sometimes people were encouraged to commit to the project, but top management had to pursue people who were not competent. This shows that project managers did not have enough meetings and communication with the project teams.

"We have project managers and resource managers as well. I think we could be better at this in our organization."

Selecting the right people for projects must be based on their competence for that particular work. Project managers have to know team competency. Effective performance by team members is expected by appropriate leadership. Leaders must help teams find the path to their goals and help them in the process (Turner and Müller 2005). Transformational leaders provide inspiration by motivating their team members through communicating high expectations (García-Morales et al. 2012). Thus, a culture that includes listening and meaningful dialogue throughout the organization is critical to effectiveness.

The findings show that in the early phase of a project, team members have some difficulty getting to know each other and building trust. Researchers from different backgrounds and different nationalities need to know each other and have the right understanding of common goals. The findings show that lack of trust and misunderstanding have negative effects on project performance and outcome. A lack of time and continuity makes it difficult for project partners to develop familiarity and to prove their good will and competence to each other. Building trust is an important but challenging task that has received little attention within the discipline of project management (Maurer 2010).

"Lack of trust can slow down the project a lot."

In the early stage of a project, available information is scarce, but the consequences of the project-related decisions are great (Williams and Samset 2010). Poor management in the early stage has a negative impact on project performance and outcome (Khurana and Rosenthal 1998). Therefore, it is important to examine employees' perceptions of the project. The findings indicate that there 
is a relationship between leadership and project performance and outcome. Informant 1 suggested that project management should allocate much more time in the early phase in order to learn about the team members. Leaders should build relationships considering each individual's needs, along with growth and achievement, creating a supportive climate to reach higher levels of potential (Limsila and Ogunlana 2008).

The findings show that project managers do not have enough time to spend with project teams. We have seen researchers who cannot perform all the tasks they are allotted because they have a lot to do. If project managers and team members are aware of the project's progress, then they can decide before the project is postponed.

Project managers, by delegating responsibilities, can help and support team members. Planning efficiency will increase. Organizations with low-control cultures and more decentralization are more likely to delegate decisions (Wiewiora et al. 2014). With the shift toward team-based knowledge work, it is necessary to revise and rethink whether the traditional model is still appropriate. Shared leadership is appropriate for knowledge-based work that has characteristics including interdependence, creativity, and complexity (Pearce and Barkus 2004). Without trust, there is no hope of developing shared leadership. Top leaders play an important role in the development of a shared-leadership culture (Pearce and Barkus 2004). Thus, the leadership style is important. Leaders are able to develop their team's interest. Communication and conscientiousness are important throughout the project lifecycle. Without the right culture and values, it takes longer, costs more, and ultimately affects the project performance and outcome. Different leadership styles are appropriate for different types of projects. The project manager's leadership style impacts project success (Müller and Turner 2007). In addition, team members' assigned leaders recognize them as individuals and look out for their interests. This shows that culture can determine the outcome of a project. Transformational leadership tends to lead to high performance on projects with a degree of innovation (de Oliveira et al. 2012). Transactional leaders motivate people to perform as expected while inspiring them to do more than originally expected (Den Hartog et al. 1997). The project manager's leadership style influences his or her perception of success in different situations (Turner and Müller 2005). Project managers ideally should possess a repertoire of leadership styles rather than just one style (Müller and Turner 2010). In some situations, a highly directive style might be better, and in other situations a strongly supportive style might be better (Rees 2008).

\section{Conclusions}

This study examined the impact of trust, commitment, and openness on research projects. Lack of trust in some projects causes delays in project delivery. The findings show that trust is an essential value that affects project performance and outcomes, particularly in the early phase of the project. Honesty is considered as a practiced and promoted value in the organization under study and can be considered a key factor in promoting and encouraging the building of trust. Trust promotes cooperation and higher performance, and facilitates the exchange of information and interdependencies. It also reduces control and increases efficiency.

The impact of commitment as a practiced value was also investigated regarding project performance and outcome. The level of commitment to a research project depends on the researchers' level of interest in the project. In other words, researchers prioritize their tasks based on their interests and choices. The most common motivation for carrying out research projects is freedom to prioritize tasks based on interest. Flexibility to select and complete tasks also can have a negative effect on project performance. Some projects will not be completed on time due to this freedom and flexibility. Besides that, the findings show that when researchers feel they are assets to the organization and feel that they belong, they have a stronger sense of commitment to the project.

In the early phase of a project, it is very important to make sure that everybody understands the project's objectives and knows what they are supposed to do. In addition, project team members have to know who the right person to communicate with is. These findings show that effective interactions 
among researchers can facilitate the alignment of goals and expectations. In a flat organization, people are willing to share their knowledge through effective communication. In the early phase of a project, effective communication as a promoted value helps to avoid misunderstanding. Adequate communication helps to develop shared understanding, improves the atmosphere of relationships, fosters commitment, and ensures that deadlines are respected.

Finally, this study identifies some causes of research project failure and postponement, including poor understanding of the objectives in the early phase, lack of effective communication, insufficient resources due to project teams being chosen based on previous experience with project managers (i.e., the way in which tasks are assigned to researchers), and commitment by researchers being based on their interest in the field. The findings show that project managers' leadership skills can increase the positive impact of trust, commitment, and openness on project performance and outcome. Project managers who engage in frequent, open, and effective communication can increase researchers' commitment to projects and have a positive effect on project performance and outcome. Project managers' leadership skills can reduce monitoring and control cost, which has a positive effect on project outcome. Thus, project management has an important role in involving team members, engaging in effective communication, and collaborating inside and outside of the organization. Leadership factors and organizational factors can directly impact project performance.

There are limitations regarding the reliability and validity of this research due to the small number of participants in this study. To overcome that, we used in-depth interviews. At this endpoint, for further research, we suggest more quantitative methods to identify more practiced values and categorize them based on their impact on the success of research projects.

Supplementary Materials: The following are available online at www.mdpi.com/2076-0760/7/2/22/s1.

Acknowledgments: We wish to acknowledge the Norwegian Research Council, SINTEF and NTNU who funded the research on which this was based. Thank too to all the informants, researchers, research leaders, and research project managers who were involved in this research as interviewees.

Author Contributions: Masoumeh Ghazinejad conceived the research and designed the methodology with the supervision of Bassam Hussein. Masoumeh Ghazinejad conducted the research with supervision of Bassam Hussein. Masoumeh Ghazinejad in consultation with Bassam Hussein analyzed the qualitative data. Masoumeh Ghazinejad made the analysis and wrote the report in consultation with Bassam Hussein. Youcef Zidane wrote this paper based on Masoumeh Ghazinejad's report; Bassam Hussein participated in the revision of this paper.

Conflicts of Interest: The authors declare no conflicts of interest.

\section{References}

Alvesson, M. 2002. Understanding Organizational Culture. Thousand Oaks: SAGE.

Aubert, Benoit A., and Barbara L. Kelsey. 2000. The Illusion of Trust and Performance. No. 2000s-03; Montréal: CIRANO.

Bass, B. M. 1999. Two Decades of Research and Development in Transformational Leadership. European Journal of Work and Organizational Psychology 8: 9-32. [CrossRef]

Basu, Vedabrata, Edward Hartono, Albert L. Lederer, and Vijay Sethi. 2002. The impact of organizational commitment, senior management involvement, and team involvement on strategic information systems planning. Information and Management 39: 513-24. [CrossRef]

Bstieler, Ludwig. 2006. Trust Formation in Collaborative New Product Development. Journal of Product Innovation Management 23: 56-72. [CrossRef]

Cicmil, S., T. Williams, J. Thomas, and D. Hodgson. 2006. Rethinking Project Management: Researching the actuality of projects. International Journal of Project Management 24: 675-86. [CrossRef]

Cserháti, Gabriella, and Lajos Szabó. 2014. The relationship between success criteria and success factors in organisational event projects. International Journal of Project Management 32: 613-24. [CrossRef]

de Oliveira, M. A., O. Possamai, L. V. O. Dalla Valentina, and C. A. Flesch. 2012. Applying Bayesian networks to performance forecast of innovation projects: A case study of transformational leadership influence in organizations oriented by projects. Expert Systems with Applications 39: 5061-70. [CrossRef] 
Den Hartog, D. N., J. J. Van Muijen, and P. L. Koopman. 1997. Transactional versus transformational leadership: An analysis of the MLQ. Journal of Occupational and Organizational Psychology 70: 19-34. [CrossRef]

Dey, Ian. 1993. Qualitative Data Analysis. London: Routledge.

Dyer, Jeffrey H., and Wujin Chu. 2003. The Role of Trustworthiness in Reducing Transaction Costs and Improving Performance: Empirical Evidence from the United States, Japan, and Korea. Organization Science 14: 57-68. [CrossRef]

Erkutlu, H. 2012. The impact of organizational culture on the relationship between shared leadership and team proactivity. Team Performance Management 18: 102-19. [CrossRef]

Ferrin, Donald L., and Kurt T. Dirks. 2003. The Use of Rewards to Increase and Decrease Trust: Mediating Processes and Differential Effects. Organization Science 14: 18-31. [CrossRef]

Fowler, Jeremy J., and Pat Horan. 2007. Are Information Systems' Success and Failure Factors Related? An Exploratory Study. Journal of Organizational and End User Computing 19: 1-22. [CrossRef]

García-Morales, Víctor Jesús, María Magdalena Jiménez-Barrionuevo, and Leopoldo Gutiérrez-Gutiérrez. 2012. Transformational leadership influence on organizational performance through organizational learning and innovation. Journal of Business Research 65: 1040-50. [CrossRef]

Gulzar, Mohsin, Naeema Arshad, Ebtisam Mirza, Maria Hafeez, and Nadeem Ehsan. 2012. The impact of employees' project commitment and its effect on IT industry of Pakistan. Procedia Technology 1: 258-61. [CrossRef]

Hussein, Bassam. 2013. Factors Influencing Project Success Criteria. Paper presented at the 2013 IEEE 7th International Conference on Intelligent Data Acquisition and Advanced Computing Systems (IDAACS), Berlin, Germany, September 12-14; pp. 566-71.

Hussein, Bassam A., and Kristin H. Hafseld. 2016. Organisational influences impacting user involvement in a major information system project: A case study in a governmental organisation. International Journal of Project Organisation and Management 8: 24-43. [CrossRef]

Kadefors, Anna. 2004. Trust in project relationships-Inside the black box. International Journal of Project Management 22: 175-82. [CrossRef]

Khurana, Anil, and Stephen R. Rosenthal. 1998. Towards Holistic "Front Ends" in New Product Development. Journal of Product Innovation Management 15: 57-74. [CrossRef]

Koufteros, Xenophon A., Greg E. Rawski, and Rauniar Rupak. 2010. Organizational Integration for Product Development: The Effects on Glitches, On-Time Execution of Engineering Change Orders, and Market Success. Decision Sciences 41: 49-80. [CrossRef]

Limsila, Kedsuda, and Stephen O. Ogunlana. 2008. Performance and leadership outcome correlates of leadership styles and subordinate commitment. Engineering, Construction and Architectural Management 15: 164-84. [CrossRef]

Mahdi, Omar Rabeea, Erzan Shafizan Bin Gulam Mohd, and Mahmoud Khalid Almsafir. 2014. Empirical Study on the Impact of Leadership Behavior on Organizational Commitment in Plantation Companies in Malaysia. Procedia Social and Behavioral Sciences 109: 1076-87. [CrossRef]

Maurer, Indre. 2010. How to build trust in inter-organizational projects: The impact of project staffing and project rewards on the formation of trust, knowledge acquisition and product innovation. International Journal of Project Management 28: 629-37. [CrossRef]

McLeod, Laurie, and Stephen G. MacDonell. 2011. Factors that affect software systems development project outcomes: A survey of research. ACM Computing Surveys 43: 1-56. [CrossRef]

Meyer, John P., Natalie J. Allen, and Catherine A. Smith. 1993. Commitment to organizations and occupations: Extension and test of a three-component conceptualization. Journal of Applied Psychology 78: 538-51. [CrossRef]

Mowday, Richard T. 1998. Reflections on the study and relevance of organizational commitment. Human Resource Management Review 8: 387-401. [CrossRef]

Mowday, Richard T., Richard M. Steers, and Lyman W. Porter. 1979. The measurement of organizational commitment. Journal of Vocational Behavior 14: 224-47. [CrossRef]

Müller, Ralf, and J. Rodney Turner. 2007. Matching the project manager's leadership style to project type. International Journal of Project Management 25: 21-32. [CrossRef]

Müller, Ralf, and Rodney Turner. 2010. Leadership competency profiles of successful project managers. International Journal of Project Management 28: 437-48. [CrossRef] 
Pearce, C. L., and B. Barkus. 2004. The Future of Leadership: Combining Vertical and Shared Leadership to Transform Knowledge Work [and Executive Commentary]. The Academy of Management Executive 18: 47-59. [CrossRef]

Pinto, Mary Beth, and Jeffrey K. Pinto. 1990. Project team communication and cross-functional cooperation in new program development. Journal of Product Innovation Management 7: 200-12. [CrossRef]

Pinto, Jeffrey K., and John E. Prescott. 1988. Variations in Critical Success Factors over the Stages in the Project Life Cycle. Journal of Management 14: 5-18. [CrossRef]

PMI-Project Management Institute. 2013. A Guide to the Project Management Body of Knowledge (PMBOK®Guide), 5th ed. Newtown Square: PMI Inc.

Rees, D. 2008. Managing culture. In Gower Handbook of Project Management, 4th ed. Gower: Gower Handbook of Project Management, pp. 817-24.

Rousseau, Denise M., Sim B. Sitkin, Ronald S. Burt, and Colin Camerer. 1998. Not so different after all: A cross discipline view of trust. The Academy of Management Review 23: 393-404. [CrossRef]

Schein, Edgar H. 2010. Organizational Culture and Leadership. San Francisco: Jossey-Bass, vol. 4.

Small, Jocelyn, and Derek Walker. 2011. Providing structural openness to connect with context. International Journal of Managing Projects in Business 4: 389-411. [CrossRef]

Smyth, Hedley, Magnus Gustafsson, and Elena Ganskau. 2010. The value of trust in project business. International Journal of Project Management 28: 117-29. [CrossRef]

Turner, J. Rodney, and Ralf Müller. 2004. Communication and Co-operation on Projects between the Project Owner as Principal and the Project Manager as Agent. European Management Journal 22: 327-36. [CrossRef]

Turner, John Rodney, and Ralf Müller. 2005. The project manager's leadership style as a success factor on projects: A literature review. Project Management Journal 36: 49-61.

Van Den Hooff, Bart, and Jan A. De Ridder. 2004. Knowledge sharing in context: The influence of organizational commitment, communication climate and CMC use on knowledge sharing. Journal of Knowledge Management 8: 117-30. [CrossRef]

Wiewiora, Anna, Glen Murphy, Bambang Trigunarsyah, and Kerry Brown. 2014. Interactions between Organizational Culture, Trustworthiness, and Mechanisms for Inter-Project Knowledge Sharing. Project Management Journal 45: 48-65. [CrossRef]

Williams, T., and K. Samset. 2010. Issues in front-end decision making on projects. Project Management Journal 41: 38-49. [CrossRef]

Wong, Wei Kei, Sai On Cheung, Tak Wing Yiu, and Hoi Yan Pang. 2008. A framework for trust in construction contracting. International Journal of Project Management 26: 821-29. [CrossRef]

Yazici, H. J. 2009. The role of project management maturity and organizational culture in perceived performance. Project Management Journal 40: 14-33. [CrossRef]

Zehir, Cemal, Yasin Sehitoglu, and Ebru Erdogan. 2012. The Effect of Leadership and Supervisory Commitment to Organizational Performance. Procedia-Social and Behavioral Sciences 58: 207-16. [CrossRef]

Zidane, Youcef J. T., Bassam A. Hussein, Johann Ørn Gudmundsson, and Anandasivakumar Ekambaram. 2016. Categorization of organizational factors and their impact on project performance. Procedia-Social and Behavioral Sciences 226: 162-69. [CrossRef]

(c) 2018 by the authors. Licensee MDPI, Basel, Switzerland. This article is an open access article distributed under the terms and conditions of the Creative Commons Attribution (CC BY) license (http://creativecommons.org/licenses/by/4.0/). 